\title{
MANAGING SUSTAINABILITY WITH ECO-BUSINESS INTELLIGENCE INSTRUMENTS
}

\author{
Valentin, GRECU ${ }^{1}$ and Silviu, NATE ${ }^{2}$ \\ "Lucian Blaga" University of Sibiu, Romania, valentin.grecu@ulbsibiu.ro \\ "Lucian Blaga" University of Sibiu, Romania, silviu.nate@ulbsibiu.ro
}

\begin{abstract}
In response to increasing concerns of society about environmental degradation and increasing demands for a transition to a more sustainable society, the business companies are increasingly active in aligning their processes and services with a sustainability agenda. Production, distribution and supply of goods and services require material and energy consumption, having an impact on natural resources both quantitatively and qualitatively, generating waste, pollution and disrupting ecosystems. Ecobusiness intelligence is the capacity of people, processes and applications / tools to organize business information, to facilitate consistent access to them and analyse them in order to improve management decisions, for better performance management of the organizations that are increasingly pressed to synchronize their processes and services with a sustainable development agenda, through the development, testing and implementation of decision support software. This paper advances the idea that BI methods and tools have an important but as yet not well studied role to play in helping organizations implement and monitor sustainable and socially responsible business practices.
\end{abstract}

KEY WORDS: sustainable management, business intelligence, eco-BI systems.

\section{INTRODUCTION}

Planet Earth has a limited capacity to meet the growing demand for natural resources made by socio-economic systems and to absorb the destructive effects of their use. The impacts of overconsumption of resources have begun to have measurable negative effects both on socio-economic development and people's quality of life in vast areas of the planet [1].

A good management of environmental services has now become the focus of many business strategies tending to the aspiration of 'greening' their infrastructures and product deliveries. The growing demand for "green" products has created major new markets in which visionary entrepreneurs reap the rewards of approaching sustainability [2]. Hence, by adopting sustainable practices, companies can gain competitive advantage, increase market share and boost shareholder value.

During 1960-1970, marketing and strategic management broke into management thinking, both being based on the theory of "turmoil in the business" by Igor Ansoff. Thus, companies have started to collect information about competitors, initially focusing on tactical and operational sales and marketing. As a result, information about competitors, although limited, have become part of business plans.

The competitive intelligence process continually seeks to detect any signs of change, analysis, trends and responses, opportunities and new threats to hold at any given time updated information. If we were to consider competitive intelligence as a tool that will increase competitiveness, we see that it brings significant improvements to the products and services offered by the company.

Business Intelligence (BI) has an important role to play in helping organizations implement and monitor sustainable practices. The focus should be on one phase of any BI project, the information planning phase, i.e., the systematic way of defining relevant information in order to integrate it in reporting activities.

\section{UNDERSTANDING INTELLIGENCE}

\subsection{Competitive Intelligence}

From the point of view of Craig S. Fleisher and David L. Blenkhorn [3, p.7], competitive intelligence can be understood from two perspectives. The first perspective is that of looking like a progression from raw inputs to final outputs. In this case, it starts from the raw data chunks, which are then organized by experts and processed into information. This information becomes intelligence products when placed in decision making. Thus, competitive intelligence is the intelligence refined product that meets the needs of a decision maker to understand a competitive aspect of the internal and / or external environment.

The second perspective of understanding the competitive intelligence is seen as an organizational function. Effective intelligence activities range from the wider business intelligence area to the narrowest analysis of competitors. They can provide the foundation upon which are built market strategies and tactics. As a function mainly staff oriented, competitive intelligence will overlap and reduce other functions, particularly those associated with marketing and planning.

So competitive intelligence plays an extremely important role in the strategic management of a company. This is mainly due to the fact that it has the function of early warning regarding threats to the interests and objectives of business organizations. But it must be emphasized that the information collected can not be of real use only when administered in an intelligent way. 
In order to address competitive intelligence and all that it entails in a private organization, it is necessary to understand the meaning of terms such as business intelligence, counterintelligence, information flow, and benchmarking. These processes are closely interconnected, and their implementation in an appropriate manner can lead to a better positioning.

\subsection{Business Intelligence}

One of the best definitions of business intelligence was provided by the American consulting and IT research company Gartner. According to its experts, such a concept can be defined as "the ability of people, processes and applications / tools to organize information, to facilitate access to them and analyze them to improve decisions, for better performance management" [4].

Large companies, under increasing pressure of chaotic changes that occur in the market and increasing competition, are increasingly required to develop a system of external data collection and processing them into intelligence, leading to a better functioning of the decision-making process, and therefore success in business.

Therefore, business intelligence cannot be considered a system or a product, but a concept that spans strategy, databases, and applications. Collection, recovery and analysis helps to understand trends, to highlight the strengths and weaknesses of both the own company and competitors.

Business intelligence is not addressed only big companies but also small and medium enterprises, i.e. everyone who need information to better development.

\subsection{Competitive Counter - Intelligence}

Another component of business intelligence community is the protection of the company, known in technical terms as the competitive counter - intelligence.

Counterintelligence "aims to neutralize the collection efforts of a competitor through a series of imaginative, flexible and active measures" [5, p.5].

Counterintelligence "deals with intrusions that are not illegal. There can be used barriers to prevent an exodus of information, but they must be placed in company procedures and in the minds of employees, not on points of entry sites" [6, p.184].

The counterintelligence action is a multi-layered protection that hides own weaknesses from those who, knowing them, can get benefits. Counterintelligence is also used to limit exposure to those strengths that will let them know. "It's an ongoing process by which an organization sees itself from its competitors' perspective, in order to lock the exposure to economic terrorism, cyber and industrial, fraud, negligence, unlawful acquisition of information and other security risks" [7, p.79].

\section{BACKGROUND: ECONOMIC GROWTH VERSUS SUSTAINABILITY}

Sustainability and sustainable development belong to the category of contested concepts which hold different meanings for different actors and bring forth a variety of different ways of framing the problem at stake. An important and strongly debated aspect in sustainability is the relationship between economic development and the environment. As reported by Cole [8], on the one hand global institutions and national governments typically argue that only economic growth can provide the resources with which to tackle environmental problems. Along with this idea, there is the belief in technological innovation that would lead to the discovery of new resources and thus an improvement of other dimensions such as life expectancy, housing, nutrition, and education levels in both the developed and the developing world [8, 9]. However, industrial expansion has also been identified at the root cause of environmental and social degradation and should therefore be restrained [1].

In the paper "Economic growth-the essence of sustainable development" [9], Anderson and Huggins argue that "this gloom-and-doom theory has been resurrected under the guise of sustainable development, calling for changes in virtually every aspect of our consumption and production." The amorphous nature of the concept 'sustainability' [10] means that it is impossible to state the precise relationship between sustainable development and economic growth.

Regardless the viewpoint that one may agree with, evidence of Planet's degradation is mounting. Concerns for resources depletion go hand in hand with concerns about resource quality and general systemic changes of the natural systems' services. Our overconsumption and fixation for more and more growth is killing our planet [11]. The largely empirical focus of this emerging literature can be understood by taking into account the needs of short-term exchange of information in a fast changing environment and hybrid scientist-practitioner perspective of many people involved in, and evaluating sustainability initiatives in higher education. Given the early stage of this area of research, the emerging body of research seems to have a minimum of cohesion and a degree of repetition and redundancy. In addition, a strong base of theoretical research agenda has not been established.

\section{SUSTAINABLE BUSINESS PRACTICES}

In a world facing increasing environmental, social and economic challenges, business companies have been charged with the task of aligning their processes and services with a sustainability agenda. However, the concept of sustainability is complex, interdisciplinary and contested. Approaches to sustainable businesses may range from the development of new technologies for increased efficiency to reframing technological uses and pursuing more fundamental changes within the ingrained culture of the organization. Furthermore, while all business enterprises can make a contribution towards sustainability, the ability to make a difference varies greatly by sector and organization size.

Many business strategies aspiring to 'greening' their infrastructures and product deliveries focus on the management of environmental services. The growing demand for "green" products has created major new markets in which visionary entrepreneurs reap the rewards of approaching sustainability [2]. Hence, by adopting sustainable practices, companies can gain competitive advantage, increase market share and boost shareholder value.

There has been an increased pressure on enterprises to broaden the focus of sustainability and accountability in business performance beyond that of financial performance. Demands for sustainability management spring from a variety of sources, including societal mandates incorporated into regulations, fear of loss of sales, and a potential decline in reputation if a firm does not have a tangible commitment to corporate sustainability management $[12,13]$. 
Corporate sustainability is not just a buzzword-for many industry leaders and corporations, it has become an invaluable tool for exploring ways to reduce costs, manage risks, create new products, and drive fundamental internal changes in culture and structure. However, integrating sustainability thinking and practice into organizational structure is not a trivial task and it requires a vision, commitment and leadership. It also requires a systems approach with an appropriate management framework that enables design, management and communication of corporate sustainability policies [14].

Industrial systems cause and determine flows of material and energy in society and are therefore an important part of the human economy. Although industry is sometimes seen as a source of environmental degradation and social concerns, it is widely recognized that it is an essential part of development and wealth creation. Therefore, as an important social actor, industry must play a prominent role in creating a sustainable future [15].

The challenge of sustainable development for any business is to ensure that it contributes to a better quality of life today without compromising the quality of life of future generations. If industry is to respond to this challenge, it needs to demonstrate a continuous improvement of its triple bottom line, i.e. economic, social, and environmental performance, within new and evolving governance systems [14].

Furthermore, environmental (e.g. climate change) and social (e.g. accountability) demands from shareholders and stakeholders are contributing to the pressure for companies to consider sustainability issues more seriously. However, the major challenge to companies and industries is to demonstrate their current contribution to the society as a whole without compromising the potential for continuing to deliver improvements or future generations. In short, sustainability management practices at a firm level may help the management board to align its corporate and business strategy and to meet key sustainability challenges [16].

However, increasingly, a second major reason for incorporating sustainability into business practice is starting to emerge: it makes business sense to be more sustainable. In their recent report, the World Business Council for Sustainable Development (WBCSD) and the International Institute for Sustainable Development (IISD) identify a number of business benefits of addressing sustainable development concerns [17]:

- Cost savings due to cleaner production methods and innovation-innovation and technology can improve material, energy and product efficiencies;

- Lower health and safety costs - a safe and healthy environment for workers and the community improves wellbeing, which translates into higher productivity, reduced compensation and damage suits, and reduced costs for social services and medication;

- Lower labour costs and innovative solutions - providing good working conditions can improve motivation and productivity, lower labour absenteeism or turnover and result in fewer union disputes;

- Easy access to lenders, insurers, preferential loans and insurance rates - lower risks achieved through implementation of a sustainable development strategy may lead to lower loan rates or insurance costs;
- Best practice influence on regulation-companies that follow best practice are much better placed than their competitors to influence how standards are set and the direction of regulatory change;

- Company's reputation-a commitment to sustainable development may enhance a company's reputation and secure its social licence to operate, also helping to attract the best people to join the company;

- Market advantage - a move towards integrated supply chain management may allow building deeper relationships with customers and capturing more value by providing service rather than selling products only;

- Ethical investors - the rapid expansion of the ethical and socially responsible investment movement poses a new challenge for companies as investors screen out those associated with unacceptable social and environmental performance.

Despite urgent calls for the adoption of corporate sustainability management practices [18, 12, 13], its incorporation into corporate organizational management often remains more superficial than effective [18]. One of the reasons for this lack of integration is, according to Briassoulis [19], both that companies do not know how to measure and address the issues in a systematic way, as well as the shortfall of available tools to support sustainability management practices in concrete and operational terms.

\section{THE NECESSITY OF ECO-BUSINESS INTELLIGENCE TOOLS}

The business environment is not static, and companies that fail to see the dynamics of change and adapt, are finally defeated by those that succeed. Failure to identify risks is not related to a particular area, however failure can be identified with the mentality / culture within companies. The most likely to fail are large and arrogant companies that become cumbersome to change and unable to adapt to market developments. On the other hand, studies show that surprise attacks were not successful due to the skills of misleading the competitor or the lack of early warning signals. They were unsuccessful due to lack of accountability and believe as they happen, which led to ignoring the signs of risk. Due to lack of discernment and a formal system to overcome the deadlock in time, certain managers are waking up only when crisis strikes and the performance is low. At this point, it is already too late for recovery, both for themselves and for the company, employees and investors, which ultimately end up paying the price of management errors.

It is necessary for senior management to demand not only the information you want to possess and those that need to know. This principle applies to structures for collecting and processing information, which should provide not only information management needs (specific information required by management) and those that represent or may represent a point of utmost importance for management structures.

The flow of information and decision should be one fluid, in both senses of the chain of command, to prevent formation of undesirable vacuum. Stagnation at the decision flow of information and response is partial or total closure of the system.

Openness to new ideas, new information for decision calculated and filtered, not just focus on tradition and 
innovation can create a system capable of self-sustaining at risk. Intuition management becomes valuable when it is supported by values well aware, however, intuition turned spectrum of cognitive dissonance will certainly lead to a failure predetermined side effects.

Knowing the vulnerabilities and threats, risk assessment strategies based on tradition and innovation, monitoring information internally and externally, using internal and external tools for collecting and processing information, facilitate a continuous flow of information (flow obstructions may lead the partial or total collapse of the system) - are elements necessary for the operation management through business intelligence system

\section{A DECISION SUPPORT SYSTEM FOR MANUFACTURING - A TOOL FOR SUSTAINABLE MANAGEMENT}

Making decisions by intuition, knowing that the decision will affect the whole production process or the whole company, it's not the best way of management. That's why it's important to have a computer-based information system that supports organizational or business decision-making activities. Decision Support Systems (DSS) serve the management, operations and planning level of an organization and are helpful for making decisions, which may be rapidly changing and not easily specified in advance.

A computer-based decision support system can be easily integrated in the operational management process, assuring a fast and waste-reducing solution for issues that are often encountered in manufacturing organizations. As stated before, many organizations try to adapt to the dynamics and trends of the business environment and "greening" the production process has become a must. The following example shows the utility of such a tool that can generate competitive advantages and improve the company's image in the eyes of its clients who are increasingly demanding eco-production of goods and services.

The proposed decision support system allows the decision maker to choose the best alternative out of a set of possible interventions, based on a group of custom-defined criteria.

The system allows the use of an indefinite number of alternatives and criteria. Underlying the DSS is an innovative approach that combines two well-known algorithms: the hierarchic-analytic process, used mainly in operations management, and the advanced multi-criteria analysis based on the FRISCO formula. A detailed description of this combined algorithm may be found in the work of Grecu and Denes [20].

The developed algorithm requires good mathematical abilities from the user, and this can therefore limit the real-life applicability of the proposed decision support system. In order to make it easier to use the DSS and increase the number of potential users, the DSS was implemented online with a userfriendly interface. For this purpose, an extension for the content management system Joomla! 1.5 was developed. It can be easily integrated into any website created with Joomla! 1.5 [21]. The purpose of our approach is to offer a finite tool to decision makers by leaving the computational part to the server. We are thus allowing users to concentrate on planning issues rather than having to understand the formulas that lie behind the algorithm.

\subsection{Deciding which metal-cutting system is best}

There are so many variables to be considered when making a decision on the right cutting system to use, it is often a difficult analysis. The metal processor and, to some degree the end-user of the material, must consider at least some of the following issues:

- Cutting speed

- Edge cleanliness

- Degree of tolerance required

- Number and types of metal to be cut

- Capital investment

- Operating costs

- Size of heat affected zone

- Access to secondary machining processes

There is no one overall answer to the question "Which metal cutting system is best?" The factors that are important to one metal processor will be different from those of another depending on their customers' needs. The "best" metal cutting process depends on the material to be cut and the final application of the material. There is no cutting system that is superior to another in all major comparison categories.

\subsection{The working principle of the DSS}

For exemplification it is used a hypothetical situation for a decision in a situation for choosing the best cutting method of a material, with five decision alternatives and five selection criteria. First, the user is requested to enter the number of criteria (Figure 1) and specify (Figure 2) the name of each criterion $(\mathrm{C} 1-\mathrm{C} 5)$.

Then a quadratic matrix is generated and the user has to compare each criterion against the others. One can choose whether each criterion is more important, equally important or less important than other criteria (Figure 3). It is important to remember that the relationships between criteria are the choice of the decision maker.

This choice can be based on experience, literature review, statistic evidence or other specific needs. This step basically establishes a hierarchy of the chosen criteria and each criterion is given a weight.

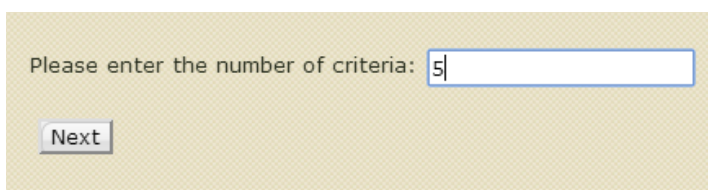

Figure 1. Choosing the number of criteria

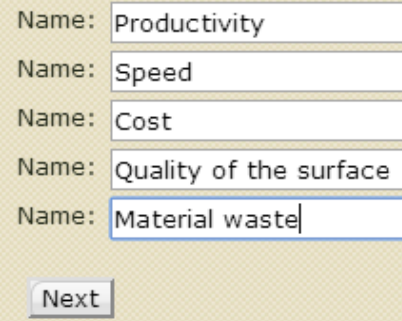

Figure 2. Naming the criteria 


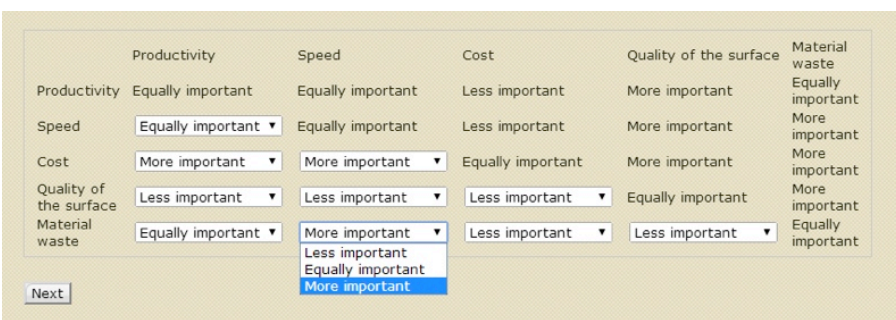

Figure 3. Comparing the criteria

Then, the user is asked to enter the number of decision alternatives (Figure 4), to define/name them (Figure 5) and then to compare each alternative against the others based on how they satisfy each criterion (Figure 6). For example, when the alternatives are compared considering the criterion "Cost", the cheaper alternative is considered "more important".

\section{Please enter the number of alternatives: 5}

Next

Figure 4. Choosing the number of alternatives

$\begin{array}{ll}\text { Name: } & \text { Gas } \\ \text { Name: } & \text { Oxi-Electric } \\ \text { Name: Plasma } \\ \text { Name: Laser } \\ \text { Name: Water } \\ \text { Next }\end{array}$

Figure 5. Naming the alternatives

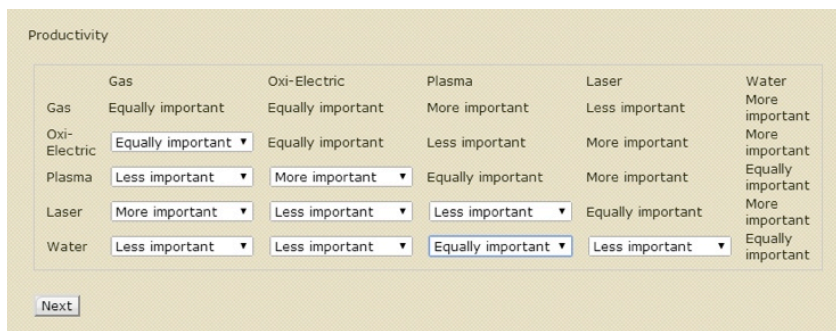

Figure 6. Comparing the alternatives based on each criterion

Congratulations for completing all steps Press the button below to view the results.

Next

Figure 7. The solution has been generated

$\begin{array}{ll}\text { Results: } & \\ \text { Alternative; } & \text { Rank } \\ \text { Gas } & 2.5 \\ \text { Oxi-Electric } & 1 \\ \text { Plasma } & 4 \\ \text { Laser } & 2.5 \\ \text { Water } & 5\end{array}$

Figure 8. The ranking of the alternatives
The software then uses the encoded mathematical algorithm and returns the optimal solution, as shown in figures 7 and 8 . This allows the decision maker to make an informed decision, based on specific needs and the particularities of each cutting method, rather than intuition.

\subsection{Other applications of the DSS}

The proposed DSS allows the decision maker to define his/her own set of decision alternatives and selection criteria, it has a virtually ubiquitous applicability, being adaptable for all decision scenarios where it is required to choose from a list of alternatives, based on a set of criteria. The proposed decision support system speeds up the decision making process and increases the quality of the management process.

Underlying the proposed DSS is an innovative approach that combines two well-known algorithms: the hierarchic-analytic process, used mainly in operations management, and the advanced multi-criteria analysis based on the FRISCO formula. The developed algorithm requires good mathematical abilities from the user, and this can therefore limit the real-life applicability of the proposed decision support system. In order to make it easier to use the DSS and increase the number of potential users, it was implemented online with a user-friendly interface.

Further research may mean creating a series of databases with recommendations based on knowledge, in order to guide the user when choosing the decision criteria and their importance for the project.

\section{CONCLUSIONS}

After years of significant investment in putting in place a technological platform that supports business processes and strengthens the efficiency of operational structure, most organizations have reached a point where the use of tools to support the decision making process at the strategic level emerges as more important than ever. Herein lies the importance of the area known as business intelligence (BI), seen as a response to current needs in terms of access to relevant information through intensive use of information technology (IT) [22]. BI systems have the potential to maximize the use of information by improving the company's capacity to structure a large volume of information and make it accessible, thereby creating competitive advantage, what Davenport calls "competing on analytics" [23].

Sustainability topics are influencing the economic success of companies more than ever. Sustainability has become a driver for both risks and opportunities in business. Strategic management and information management are thus challenged to take into account sustainability information. Independent of the strength of their influence, elements of sustainability can work through market or non-market processes to have an effect on business success [24].

The starting point for an effective management of elements of sustainability relevant to business success is an understanding of their interrelationships. Building a sustainable business is a long-term and multilevel challenge which requires strategic thinking and a systems approach. Corporate sustainability is not an 'add on' but must be an integral part of business and, like all other business activities, it must be managed in an appropriate way.

Although business responses to corporate sustainability issues are varied, the core message is simple: corporate sustainability 
is a managerial issue as well as a strategic issue. Researches also indicate that a company's decision to engage in corporate sustainability management is a strategic choice [13].

The managerial approach sees BI as a process in which data gathered from inside and outside the company are integrated in order to generate information relevant to the decision-making process. The role of BI here is to create an informational environment in which operational data gathered from transactional systems and external sources can be analyzed, in order to reveal "strategic" business dimensions for the transition towards the sustainable organization.

\section{ACKNOWLEDGEMENTS}

This work was supported by the strategic grant POSDRU/159/1.5/S/133255, Project ID 133255 (2014), cofinanced by the European Social Fund within the Sectorial Operational Program Human Resources Development 2007 2013.

\section{REFERENCES}

1. Grecu, V. and Denes, C., Sustainability Management in Romania: Challenges and Opportunities, Proceedings of the 19th International Economic Conference: The Peristence of the Global Economic Crisis: Causes, Iimplications, Solutions, pp 203-212, (2012)

2. International Institute for Sustainable Development (IISD), accessed at http://www.iisd.org/business/ on 07.09.2011, (2010)

3. Fleisher, C. S. and Blenkhorn, D.L., Managing frontieres in competitive intelligence, Library of Congress Catalog (2001).

4. Gartner Research, Business Intelligence. Retrieved from IT Glossary: http://www.gartner.com/it-glossary/businessintelligence-bi/, (2014, March 8)

5. Nolan, J., Confusing Counter intelligence With Security Can Wreck Your Afternoon, 2001, p. 53. (2001)

6. West, C., Competitive Intelligence, PALGRAVE, New York, 2001, p. 184. (2001)

7. Martin, A. P., Harnessing The Power Of Intelligence, Counterintelligence And Surprise Events, Professional Dev Inst Pr Publisher, London, 2002, p. 79. (2002)

8. Cole, H.S.D., Freeman, C., Jahoda, M. and Pavitt, K.L.R. (eds). Thinking About the Future: a Critique of the Limits to Growth, Chatto and Windus for Sussex University Press. (1973)

9. Anderson, T.L., Huggins, L.E., Economic growth-the essence of sustainable development, accessed at: http://findarticles.com/p/articles/mi_m1568/is_8_35/ai_11 1574446/ on 6.09.2011 (2004)

10. Campbell, A., Participatory inquiry: beyond research and extension in the sustainability era, paper for International Symposium on Systems-Oriented Research on Agriculture and Rural Development, Montpelier, (1994).
11. Leufstedt, S., A Picture is Worth... How our economy is killing the planet, accessed at http://www.greenblog.org/2010/08/09/a-picture-is-worth-how-oureconomy-is-killing-the-planet/ on 09.09.2011 (2010)

12. Lee, K.H., Corporate Sustainability and the Value of Corporations. Pakyoungsa, Seoul, (2005).

13. Siegel, S., Green management matters only if it yields more green: an economic/strategic perspective. Academy of Management Perspectives 23 (3), 5-16, (2009).

14. Azapagic, A., Systems Approach to Corporate Sustainability: A General Management Framework, Trans IChemE, Vol 81, pp303-316, retrieved 17.04.2011 from www.ingentaselect.com $=$ titles $=09575820 . \mathrm{htm}$ (2003)

15. Azapagic, A. and Perdan, S., Indicators of sustainable development for industry: a general framework, Trans IChemE, Part B, Proc Safe Env Prot, 78(4): 243-261, (2000)

16. Schaltegger, S. and Burritt, R., Corporate sustainability. In: Folmer, H., Tieten- berg, T. (Eds.), The International Yearbook of Environmental and Resource Economics. Edward Elgar, Cheltenham, pp. 185-232 (2005).

17. IISD \& WBCSD, Mining, Minerals and Sustainable Development Project. http://www.iied.org/mmsd (4 March 2002).

18. Figge, F., Hahn, T., Schaltegger, S., Wagner, M., The sustainability balanced scorecard-linking sustainability management to business strategy. Business Strategy and the Environment 11,269-284, (2002).

19. Briassoulis, H., Sustainable development and its indicators through a (planner's) glass darkly. Journal of Environmental Planning and Management 44 (3), 409-427 (2001).

20. Grecu, V. and Denes, C., A Decision Support System for the Transition Towards the Sustainable University, Proceedings of the International Conference on Engineering \& Business Education, Innovation and Entrepreneurship, Sibiu, Romania, 18 - 21 October, 2012, pp. 319-324, (2012)

21. Grecu, V. and Rosca, L., Sa construim un site cu Joomla! (Let's build a website with Joomla!) Sibiu, Romania: Publishing house of "Lucian Blaga" University (2011)

22. Petrini, M., \& Pozzebon, M., Managing sustainability with the support of business intelligence: Integrating socioenvironmental indicators and organisational context. The Journal of Strategic Information Systems, 18(4), 178-191 (2009).

23. Davenport, T. H., Competing on analytics. Harvard Business Review,84(1), 98 (2006).

24. Schaltegger, S., Sustainability as a Driver for Corporate Economic Success. Consequences for the Development of Sustainability Management Control, Society and Economy, volume 33, issue 1, pp15-28, (2011) 